\title{
Power management system for RTG crane using fuzzy logic controller
}

\section{Article}

\section{Accepted Version}

Creative Commons: Attribution-Noncommercial-No Derivative Works 4.0

Pietrosantl, S., Alasali, F. and Holderbaum, W. (2020) Power management system for RTG crane using fuzzy logic controller. Sustainable Energy Technologies and Assessments, 37. 100639. ISSN 2213-1388 doi: https://doi.org/10.1016/j.seta.2020.100639 Available at https://centaur.reading.ac.uk/89543/

It is advisable to refer to the publisher's version if you intend to cite from the work. See Guidance on citing.

Published version at: http://dx.doi.org/10.1016/j.seta.2020.100639

To link to this article DOI: http://dx.doi.org/10.1016/j.seta.2020.100639

Publisher: Elsevier

All outputs in CentAUR are protected by Intellectual Property Rights law, including copyright law. Copyright and IPR is retained by the creators or other copyright holders. Terms and conditions for use of this material are defined in the End User Agreement.

\section{www.reading.ac.uk/centaur}

\section{CentAUR}

Central Archive at the University of Reading 
Reading's research outputs online 


\title{
Power Management System for Electrified RTG Crane Using Fuzzy Logic Controller.
}

\author{
Stefano Pietrosanti ${ }^{\mathrm{a}, \mathrm{b}^{*}}$, Feras Alasali $^{\mathrm{c}^{*}}$, William Holderbaum ${ }^{\mathrm{a}, \mathrm{d}}$ \\ a School of Systems Engineering, University of Reading, Whiteknights, Reading RG6 6AY, UK. \\ ${ }^{\mathrm{b}}$ GDS Instruments, Unit 32, Murrell Green Business Park, London Rd, Hook RG27 9GR, UK. \\ ${ }^{c}$ Department of Electrical Engineering, Hashemite University, Zarqa 13113, Jordan. \\ ${ }^{\mathrm{d}}$ School of Engineering, Metropolitan Manchester University, Manchester, UK.
}

\begin{abstract}
:
In this research, there are two major objectives have been investigated for a Rubber Tyred Gantry (RTG) crane system: energy consumption reduction and decrease the stress on the primary source. These objectives can be met by using an advance control system that reads the status of the crane and outputs a power reference value which is fed to the storage device. This paper presents Fuzzy Logic Controller (FLC) approach to maximise the potential benefits of adding energy storage units to RTG cranes. In this work, FLC is described and simulated, with the results analysed to highlight the behaviour of the storage in association with the specific control system. An actual collected data at the Port of Felixstowe, UK has been used to develop the crane and ESS models and test the proposed control strategies in this paper. Furthermore, a comparison analysis between the FLC and the standard control system (PI) for RTG crane and ESS applications will be presented with respect to energy consumption, fuel saving and the control impact on the energy device. The simulation results of the FLC control strategy for the collected data shows that it successfully increases the energy savings by $32 \%$ and outperformers the PI controller with $26 \%$.
\end{abstract}

Keywords: energy storage system; RTG crane; fuzzy logic controller; energy saving.

\section{Introduction}

\subsection{Background}

A vital element in a container terminal is the RTG crane which is used to handle containers during the process of transshipment, e.g. when transferring goods from a cargo ship to inland transport. RTG cranes consume large amount of energy when lifting containers onto stacks that can reach heights of 15 meters. On a typical day, an RTG crane can consume more than $500 \mathrm{kWh}$ in the single process of hoisting containers [1]. If equipped with an energy storage device, an RTG crane can recover up to $89 \%$ of the energy used for hoisting [1]. This energy can then be used to power subsequent lifts, reducing the energy consumption and CO2 emissions of container terminals. Due to the presence of size, weight and cost restrictions, it is necessary to use power management strategies that maximise the benefits whilst under energy and power capacity constraints. A Fuzzy Logic Controller (FLC) can be used to determine when to store or release energy depending on the status of both the crane and the Energy Storage System (ESS), increasing the overall efficiency of the whole system. This paper introduces a supervisory FLC that generates the power reference signal for an ESS with the objectives of recovering all the energy regenerated when lowering a container and using this stored energy in subsequent lifts. 


\subsection{Literature review}

An early study on ESS in cranes was presented by Liang and Virvalo in 2001, storing energy in a hydraulic system [2]. The authors proposed a hydraulic energy storage system for hydraulic cranes: accumulators store potential energy recovered from lowering loads [2]. This can be easily achieved with cranes powered by electric motors using electric energy storage systems. Firstly, the technology behind flywheel electric energy storage allowed for its use in RTG cranes. Toliyat et al. firstly introduced them in [3], where it is demonstrated how it is possible to store the energy and control the power using back-to-back converters and a permanent magnet synchronous machine. An application for this technology has been found by Flynn et al. in [4], where an RTG equipped with flywheel storage is described. The technology used has been commercialised by Vycon specifically for use in RTG cranes [5]. Supercapacitors, and later batteries, have been extensively used in RTGs. The first paper on supercapacitors in RTG cranes was presented by Kim et al. in 2006 [6] whilst batteries were first used by Baalbergen et al. only in 2009 as the energy densities and lifetime of Li-ion batteries had sufficiently improved by then [7]. These positive preliminary results and industrial involvement caused an increase in interest of the academic environment towards controlling storage in cranes to maximise the potential benefits of using ESS.

The research presented in this paper focuses on the control of energy storage, in particular controlling the power flowing to and from it in order to maximise the multiple benefits that can be potentially obtained. This is achieved in two ways: controlling the storage system by conventional control strategies such as set-point and PI controllers, ensuring that a reference power output is followed; or developing an optimal or intelligence control systems focus on obtaining benefits for the whole system. Firstly, the conventional control strategies as simplest and standard solution aim to determine a constant reference depending on the operating mode of the system. This type of controller outputs a reference value by processing the input with logic expressions; they are based on intuition and human expertise without the need of a priori knowledge of the operating cycle [8]. For example, Baalbergen et al. in [7] compares various conventional control strategies aimed at reducing the lifetime costs of equipment and fuel in hybrid RTG cranes. The most promising strategy emerging from the article consists in switching on the generator for a limited period for charging a supercapacitor bank, which in turns powers the crane for the rest of the time. The crane then fluctuates between two states: one where the storage passively powers the whole crane, and another where the generator produces constant power (at the maximum rated level). This simple but effective control strategy has also been applied by Iannuzzi et al. [9], and also by Niu et al. in [10] where a large battery powers the crane and it is recharged by the generator when reaching a low state of charge. Note that the strategies proposed in $[7,9,10]$ do not consider managing the power output of the storage, which exclusively depends on the value of the load.

Other works introduced Power Management Strategies (PMS) that tune the storage output power depending on the state of multiple inputs via the use of optimal controllers [11-13], improving rule-based controllers that are constrained by finite states and fixed output rates. Fuzzy logic can also be used to determine the storage output power depending on the state of the crane and the storage, offering high robustness and adaptivity [8].

Fuzzy Logic Controllers (FLCs) are based on fuzzy input sets and linguistic rules, selecting an output that does not need to be limited to a small number of discrete values [15, 16]. Although the use of FLCs is widespread in power systems $[8,16]$, there is currently very little research related to fuzzy logic controllers in 
hybrid RTG cranes, even though Xu in [18] recommends fuzzy control for extending his work. Fuzzy logic controllers in Hybrid Electric Vehicles (HEVs) have been the subject of extensive research, and many articles can be found presenting advanced techniques. Ignoring, for the moment, the technical differences between the operation of a hybrid RTG crane and a HEV, it is possible to look at the research related to FLCs in hybrid electric vehicles for inspiration. For example, Schouten et al. [19] show the use of a hybrid vehicle with batteries where the FLC receives as input the state of charge of the storage and the motor speed. Ferreira et al. in [20] add fuel cells and supercapacitors as well, increasing the complexity; the FLC is relatively simple, though, showing a quality of fuzzy logic: high effectiveness with low complexity. Salmasi in [8] presents other examples of noteworthy uses of FLCs in HEVs, and compares them to other existing control systems. As already mentioned, threflectere is different type of FLC and there appears to be a lack of rigorous and extensive research related to the application of FLCs to RTG cranes, compared to what is available for HEVs. The only published paper with this topic is [21], where the possibility of using an FLC is hinted but no controller is presented. However, the thesis written by Knight [22] presents in detail an FLC for flywheel storage. The control strategy is focused on reacting to changes in the voltage, with high symmetry between the consumption and regeneration phases; the behaviour of the controller is then similar to a voltage controller, with added tweaks that modify the output depending on the load and the state of charge of the storage. Whilst its performance is not at the same level of other control system in the literature, it is significant to develop an advanced FLC for hybrid RTGs.

\subsection{Contributions}

The literature shows a robust presence of papers regarding energy storage in power applications, like for example the use in electric vehicles. However, there is still only a limited number of papers focused on RTG cranes, and only few of them discuss control strategies for energy storage. This paper aims to fill the literature research gaps by

- Demonstrating a fuzzy logic controller applied to energy storage in RTG cranes that enables both energy recovery and power sharing.

- The control strategy is applied on a Matlab/Simulink model based on actual data collected over six days and under different conditions at the Port of Felixstowe, UK. It will accurately identify and quantify the energy and power flows in a crane system compared to published work on the power and energy consumption of an RTG crane by using only a normal operation cycle over only single lift cycle that last less than two minutes.

\subsection{Outline of paper}

The structure of this article is organised as follows: the topology of the flywheel storage device and RTG system are presented in Section 2. Then, the fuzzy logic controller approach is introduced. In following section, the simulation results are presented and discussed. Finally, summary of this work is discussed in Section 5.

\section{RTG Crane and ESS Topology}

The Port of Felixstowe (PoF) is the largest container port in the UK with an annual handling volume of over 4 million Twenty-foot Equivalent Unit (TEU), equivalent to 40\% of the UK container volume [24], and the port is inevitably associated with a high energy consumption. One of the major contributors in the energy consumption 
is the fleet of around 60 RTG cranes that handle containers in the terminal yards. An objective of the research presented in this paper is to reduce the energy consumption of RTG cranes, potentially leading to major energy savings and reductions in greenhouse gases emissions in PoF and any container terminal that employs RTG cranes.

The work presented in this paper is mostly based on the operation of a generic RTG, although a specific model of crane is used as a reference for simulations and analysis of the control strategies. The most prevalent model of RTG crane at PoF is a diesel-powered 16 wheels crane rated for a maximum container weight of 40 tonnes, manufactured by Shanghai Zhenhua Heavy Industries Company Limited (ZPMC).

The RTG crane under analysis, was originally powered exclusively by a diesel generator. Recently, it has been fitted and connected to the low voltage network through a conductor bar, as shown in Figure 1, allowing crane to be powered by the three-phase grid instead of using the diesel generator. In this work the source was modelled as an infinite capacity three-phase source, capable of delivering any instantaneous power $P_{g}(t) \geq 0 \forall t$ $>0$ to the DC bus through a (single-quadrant) diode rectifier. The assumptions on the primary source are justified by the fact that the power rating of the primary source will be higher than the maximum power demand of the crane. The primary source has no energy limitation as it is supposed to be either the electrical grid or a diesel generator, both capable of supplying the energy required during a lift cycle. Furthermore, the time dynamics of the electrical components of the crane are assumed to be slower than the main power source in order to guarantee the correct operation of the crane. These assumptions are justified by the consideration that RTG cranes currently operating in container terminals perform normally with their own primary supply and without any additional power source. The hoist, gantry and trolley motors are all connected to the shared DC bus and are modelled as a single load power $\mathrm{P}_{\mathrm{L}}(\mathrm{t})$ which changes with the activity; the motors regenerate power during braking so the instantaneous value of $\mathrm{P}_{\mathrm{L}}(\mathrm{t})$ can be negative. Brake resistors, as shown in Figure 2, engage automatically when the DC bus voltage raises above $750 \mathrm{~V}$, absorbing all the regenerated energy; the power dissipated into the brake resistor $P_{d}(t)$ is assumed unbounded and can only flow in a single direction: $P_{d}$ $(t) \geq 0 \forall t>0$. Hence, the power flow at the RTG crane system can be described Equation (1).

$$
P_{g}(t)=P_{L}(t)+P_{d}(t)
$$

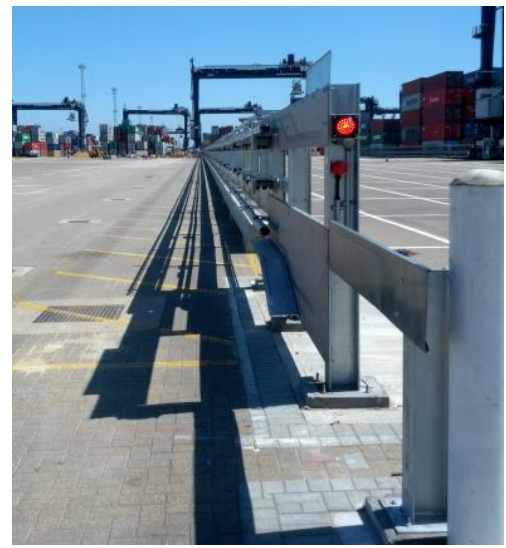

Figure 1. Three-phase conductor bar that powers RTG cranes at the Port of Felixstowe.

The power flows in RTG crane system are also visualised in Figure 2. The regenerated energy is dissipated into the brake resistors, wasting significant amounts of energy and increasing the greenhouse gases emission from RTG cranes, especially diesel powered ones. 


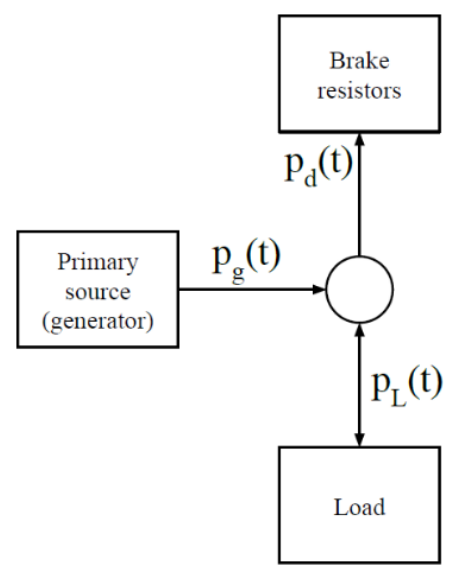

Figure 2. Diagram showing the basic topology of an RTG crane.

\subsection{The Energy Storage System (ESS): flywheel energy storage model}

Generic energy storage models offer a high flexibility and allow to simulate a wide range of technologies or an entire subset of a single technology, but they may fail at accurately reproduce a single device as they may lack complexity or, on the contrary, model dynamics which are not present in the particular system. High quality measurements obtained after the development of the previous models allowed for the creation of a specific model of a Flywheel Energy Storage System (FESS) powered by a switched reluctance motor. The specific model requires less assumptions as it is purely based on data provided by manufacturers, thus it intrinsically includes all the dynamics which are difficult to estimate, like losses and efficiency. Figure 3 shows a diagram with the various components of the model and their interconnections.

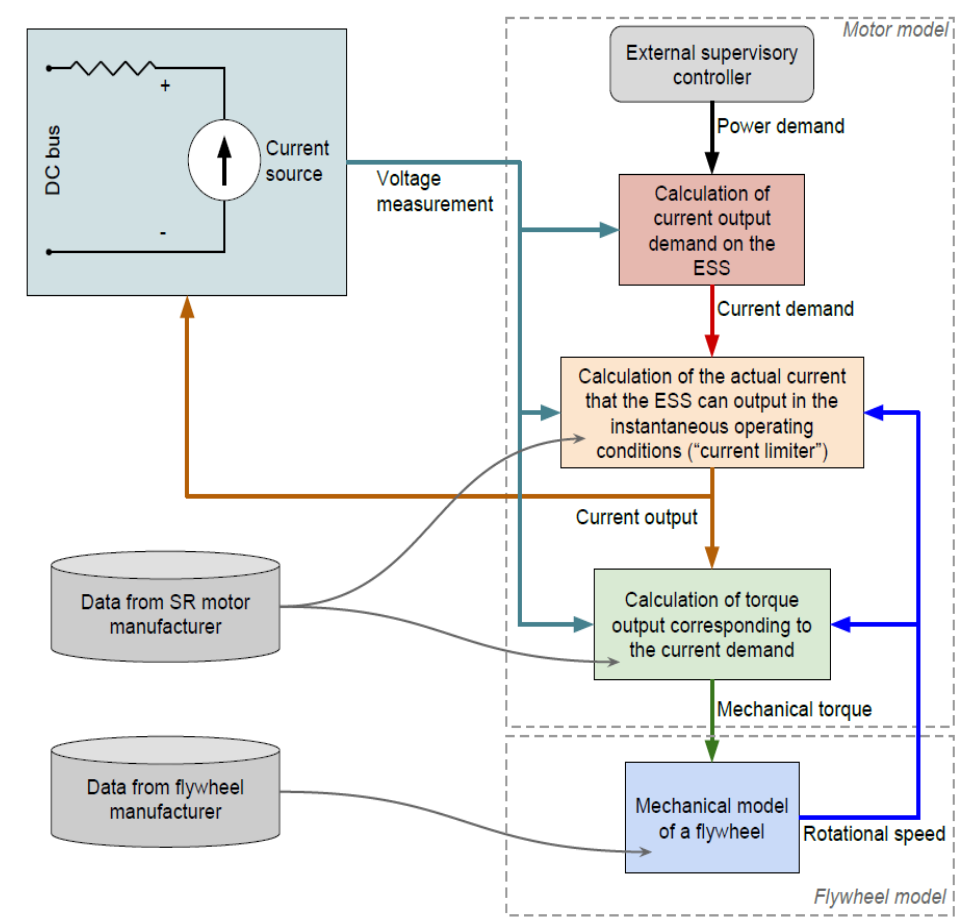

Figure 3. Diagram of the components of the specific FESS model.

In September 2016 a high-quality set of measurements were collected on a flywheel energy storage developed by CRESS Systems for RTG crane applications at PoF, allowing for a more accurate model of the flywheel to be developed. The system has been metered during spin-down phases consisting in the motor and flywheel 
slowing down from 15,000 RPM to 0 under friction and windage effects only, with the motor powered down. The flywheel motor is manufactured by Nidec SR Drives, which provided data collected during dynamic testing of the motor. The flywheel energy storage system model has been developed based on the parameters in Table 1.

Table 1. The main parameters of the flywheel energy stoarge.

\begin{tabular}{ll}
\hline \multicolumn{1}{c}{ Parameters } & \multicolumn{1}{c}{ Value } \\
\hline Power & $150 \mathrm{~kW}$ \\
Energy storage capacity & $3.34 \mathrm{MJ}$ \\
Number of poles & $12 / 10 \mathrm{pole}$ \\
Motor inertia & $3.0447 \mathrm{~kg} / \mathrm{m} 2$ \\
Max speed & $15,000 \mathrm{RPM}$ \\
Min speed & $5000 \mathrm{RPM}$ \\
\hline
\end{tabular}

\section{Fuzzy logic supervisory control.}

Given the RTG crane and ESS model and in order to maximise the potential benefits of using FESS, the next step is to design an intelligent supervisory control strategy. A Fuzzy Logic Controller (FLC) is based on fuzzy logic rules which determine the value of the control output depending on the approximate state of the inputs. For example: if the hoist motor is regenerating power, then the storage should be charged; if the hoist motor is regenerating a large amount of power, then the storage should be charged faster. Fuzzy rules allow for degrees of uncertainties on the measurements or the parameters, as the output is calculated depending on the degrees of membership of the inputs to fuzzy sets and not crisp values. The objective of using fuzzy logic control is to increase the robustness of basic PI controller, which are currently the most common controller used in hybrid RTGs. As discussed in Section 1, FLCs are widespread in other areas (e.g. hybrid electric vehicles), however for RTGs they have only been the subject of one work [22] even though Xu et al. [18] recommended their use with RTGs. Their use is then proven in similar applications and comparisons have shown that they are a viable and efficient alternative [8]. FLCs possess qualities that are favourable to the use in hybrid RTGs: their structure is based on simple logic which helps the initial development. Once implemented in a control system they act as simple inputs-to-output mapping that has no dynamic and therefore they are very easy to test when associated with complex models as the RTG one presented in Section 2. This work is based on the Mamdami FLC [16]: a fuzzification process transforms the input into fuzzy sets that are then processed using linguistic rules (if $\mathrm{X}$ then Y) in order to produce an output, which then undergoes a defuzzification process to produce the crisp output value [15]. This process is shown in Figure 4.

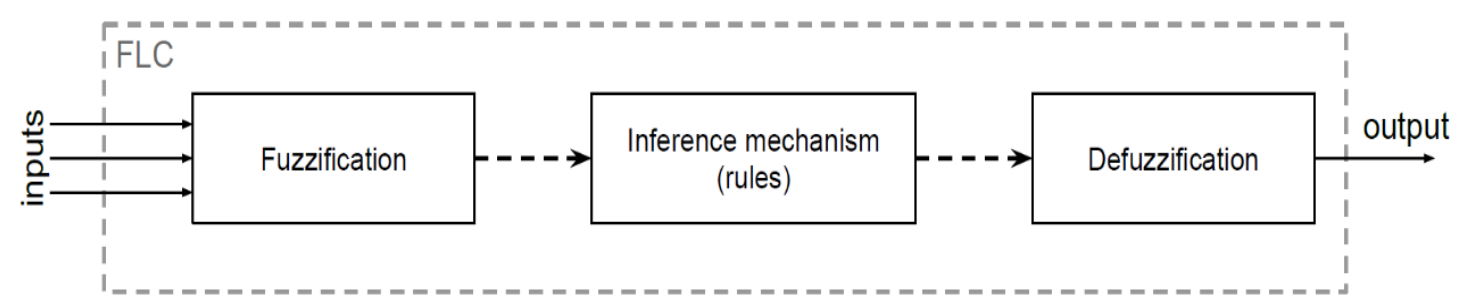

Figure 4. Structure of a fuzzy system.

Designing a FLC may require a less formal approach with respect to other controllers as it is based on intentionally vague evaluations of the inputs in order to determine the output. Nonetheless, it does not mean that 
it is simpler or easier to do so, as it requires a deeper understanding of the complex system that needs to be controlled in order to achieve the best performance and stability. In this particular case, the thorough knowledge of the operation of the RTG crane and its power flows is necessary for the development of this controller. This requirement will be evident in the following sections, where the fuzzy rules are presented and explained. A FLC is usually quite robust to changes in the parameters of the system because, as the name implies, it uses fuzzy logic and it is not necessarily bound to exact values: the power flow can be defined as "low", "medium" or "high", with very gradual and smooth boundaries between the three levels [15]. These inputs are: FESS rotational speed, power flowing to the hoist motor and DC bus voltage. The (single) output is normalised and bounded in $[-1,1]$, corresponding respectively to maximum power input and maximum power output.

\subsection{Membership functions.}

Every signal or value that is fed as an input to the controller is associated with its own set of pre-defined fuzzification functions. The actual "crisp" value of the input is not important, what matters is its degree of membership to a particular linguistic description (e.g. "high"). A DC voltage of $750 \mathrm{~V}$, in the case of a crane, can be defined as "very high" with the maximum degree, 1 . On the other hand, $650 \mathrm{~V}$ is just in between a "normal" and "high" voltage level, therefore this value is 0.5 "normal" and 0.5 "very high".

The inputs undergo a process of fuzzification through the application of membership functions $U_{M}(x)$ that map the input $\mathrm{x} \in[0,1]$ depending on their degree of membership to a particular set $\mathbf{M}$; the membership functions belong, usually, to three categories: triangular, trapezoidal or sigmoid. Trapezoidal functions are shown in Figure 5, where the intensity of power flowing through the hoist motor is classified into three different fuzzy sets: low power, medium power and high power. The thresholds pt 1 and pt 2 are arbitrarily chosen and are listed in the appendix. When the power is very low, only the "low power" condition will be active and the associated membership function $U_{l p}$ will have positive value. As the power increases and approaches pt1, $U_{l p}$ will decrease and $\mu_{\mathrm{mp}}$ will start to grow from 0 to 1 , because the power can now be defined as "medium power". The three inputs that need fuzzification are: flywheel speed, hoist power and DC bus voltage. The parameters chosen for the membership functions are based on the power flows and the activity of the crane. The values presented in this paper are the result of a trial-and error process guided by the knowledge acquired analysing RTG data and results obtained from other control strategies. All the membership functions are visualised in Figure 7a-c and are also described in the sections below.

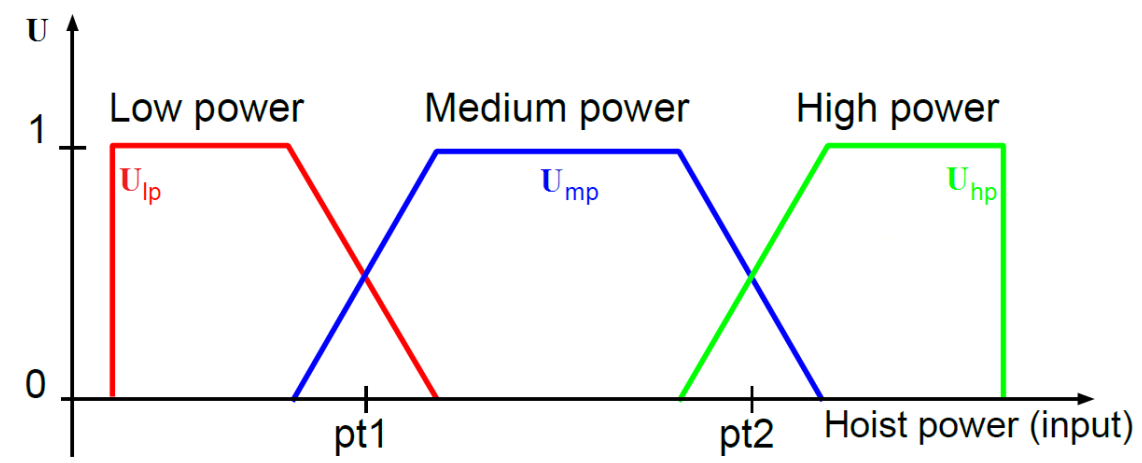

Figure 5. The membership functions for a FLC. 


\subsubsection{Flywheel speed}

The speed of the flywheel storage is bounded, therefore its power flow needs to be restricted near the limit values. The membership function $U_{\text {lowspeed }}$ linked to the first input FESS speed (in RPM) is used to maintain the storage in the charge limits as in [24]:

$$
U_{\text {lowSpeed }}= \begin{cases}1, & \text { FESSspeed }<5000 \\ -\frac{\text { FESSspeed }}{200}+\frac{5200}{200}, & 5000 \leq \text { FESSspeed }<5200 \\ 0, & \text { otherwise }\end{cases}
$$

where the lower limit is 5000 RPM and 5200 RPM is the highest value of the lowSpeed fuzzy set. The values in $\mathrm{U}_{\text {lowspeed }}$ have been chosen to achieve a soft transition to this fuzzy state, avoiding a sudden change in control output. The set normalSpeed is associated to the normal operating speeds of the storage. It is characterised by a degree of membership 1 for a very large proportion of the admissible FESS speeds:

$$
U_{\text {normalSpeed }}= \begin{cases}0, & \text { FESSspeed }<5000 \\ \frac{\text { FESSspeed }}{200}-\frac{5200}{200}, & 5000 \leq \text { FESSspeed }<5000 \\ 1, & 5200 \leq \text { FESSspeed }<14800 \\ -\frac{\text { FESSspeed }}{200}+\frac{5200}{200}, & 14800 \leq \text { FESSspeed }<15000 \\ 0, & \text { FESSspeed } \geq 15000\end{cases}
$$

Unlike similar FLCs developed for batteries, as in [17, 19], there is no differentiation between a low state of charge and a high one, as flywheel storage does not degrade when deep discharged and the FESS used in this research can provide maximum power at any allowed speed. A similar membership function as the low Speed is applied to the "high" speed set highSpeed, where the upper boundary is set to 15000 RPM, which is the maximum rotating speed of the flywheel. The membership functions described are shown in Figure 7a and listed in the appendix.

\subsubsection{Hoist power}

The second input, Hoist Power in W, is the power flowing to the hoist motor, and it is positive if the motor is demanding power. The fuzzy sets depend on the sign of the power (Negative, Positive or Zero) and are categorised as High, Medium and Low depending on the intensity. For example, if the hoist power is "positive high" then it will belong to the set $\mathbf{P H}$, from the initials of Positive and High. If the power is "negative medium", the set will be NM. The last set, POS, is only used to identify whether the power is positive or negative, therefore it will be active if the power is positive. As an example, the membership function $U_{\mathrm{NH}}$ is presented below:

$$
U_{N H}= \begin{cases}1, & \text { HoistPower }<350000 \\ -\frac{\text { HoistPower }}{150000}+\frac{2000000}{150000}, & 350000 \leq \text { HoistPower }<-20000 \\ 0, & \text { otherwise }\end{cases}
$$


The values that compose this function are chosen to provide a smooth transition between fuzzy sets. The fuzzy sets that define the power level are the following: NH, NM, NL, Z, PL, PM, PH, POS. The 8 membership functions are shown in Figure $7 \mathrm{~b}$ and listed in the appendix. The rules related to these power levels will specify the amount of power that the ESS needs to provide depending on the power level of the hoist motor: intuitively, the higher the intensity, the higher the ESS power output.

\subsubsection{DC bus voltage}

The third and last input to the FLC is the DC bus voltage (in V) DCbusV. When the crane is idle the voltage will fluctuate around $600 \mathrm{~V}$, therefore the energy storage should be kept inactive at that voltage level. During a lift, motors demand power lowering the DC bus voltage: the voltage will then be defined as "low" (L). However, a dramatic increase in voltage should determine an activation of the energy storage in order to absorb the regenerated energy: this happens in the "high" $(\mathbf{H})$ and "very high" $(\mathbf{V H})$ states of the voltage. An additional voltage state, "zero" $(\mathbf{Z})$, is used to indicate an extreme condition determined by very low bus voltage. Below is the membership function linked to the "normal" voltage state, $\mathrm{U}_{\mathrm{N}}$ :

$$
U_{N}= \begin{cases}0, & \text { DCbus } V<550 \\ \frac{\text { DCbusV }}{25}-\frac{550}{25}, & 550 \leq \text { DCbus } V<575 \\ 1, & 575 \leq D \text { Cbus } V<600 \\ -\frac{D \text { Cbus } V}{100}+\frac{700}{100}, & 600 \leq D \text { Cbus } V<700 \\ 0, & \text { DCbus } V \geq 700\end{cases}
$$

This function has output 1 when the voltage is between 575 and $600 \mathrm{~V}$, which are voltages associated with an idle crane. Then the fuzzy set transitions to 0 as the voltage deviates from the norm. The fuzzy sets for the input DCbusV are the following: $\mathbf{Z}, \mathbf{N}, \mathbf{L}, \mathbf{H}, \mathbf{V H}$, similar to what has been done previously in [17]. The membership functions are shown in Figure 7c and listed in the appendix. Furthermore, Figure 6 summarises the fuzzification process showing the three inputs and the associated fuzzy sets.

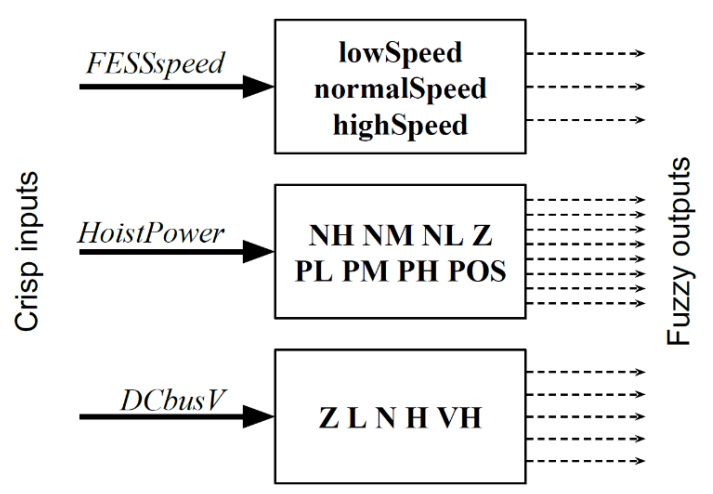

Figure 6. Fuzzification process of the three inputs and their associated fuzzy sets.

\subsubsection{Output}

The fuzzy sets defined for the inputs are then linked via a linguistic rule to an output state, which will be used later to calculate the (crisp) output value of the controller. In this work, 7 output states have been defined 
following a similar strategy to the one presented in [17]: the storage is either importing (charging) or exporting (discharging) power at a low, high or very high intensity. There is also a "zero" state $(\mathbf{Z})$ that is related to a zerooutput power. The fuzzy states are, in order from maximum import to maximum export, are: import very high (IVH), import high (IH), import low (IL), zero (Z), export low (EL), export high (EH), and export very high (EVH). The membership functions are shown in Figure $7 \mathrm{~d}$ and listed in the appendix. An example of an output membership function is the following:

$$
U_{E H}= \begin{cases}\frac{i}{0.5}-\frac{0.5}{0.5}, & 0.5<i<1 \\ -\frac{i}{0.5}+\frac{1.5}{0.5}, & 1 \leq i<1.5 \\ 0, & \text { otherwise }\end{cases}
$$

where $\mathrm{i}$ is the control output.

The inputs and output of the FLC are summarised in Table 2, with each signal associated to a particular symbol that identifies it in the rules definition. The following section will discuss how logic rules can link input fuzzy states to each of the output states.

Table 2. Input and output signals of the FLC with their associated symbols.

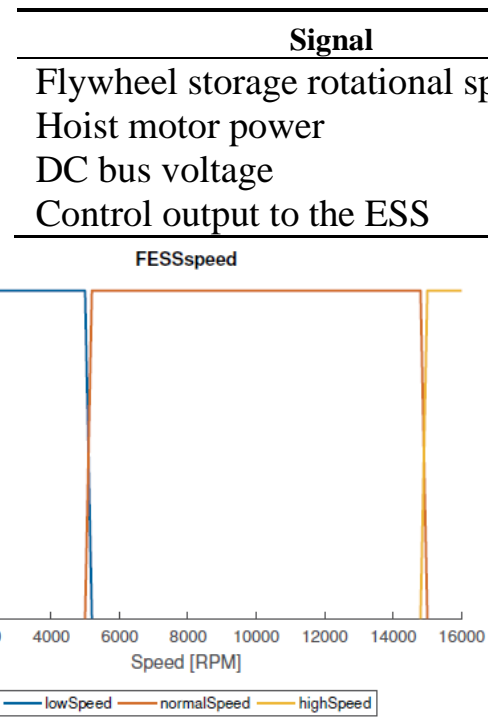

(a) input membership function 1: FESS speed

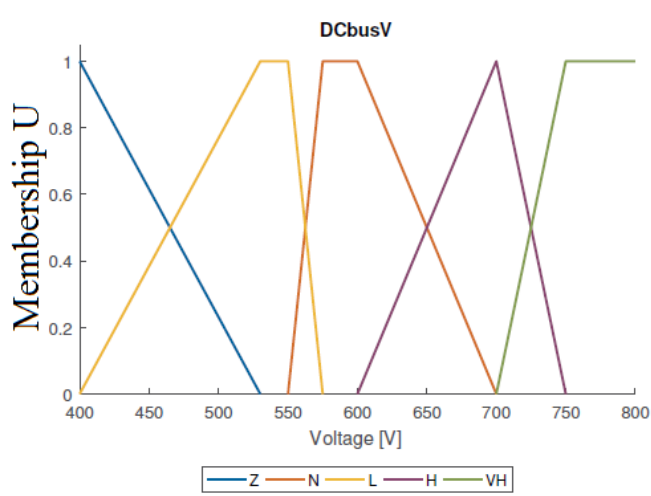

(c) input membership function 3: bus voltage

\begin{tabular}{cc} 
Type & Symbol \\
Input & FESSspeed \\
Input & HoistPower \\
Input & DCbusV \\
Output & ESScontrol \\
\hline & HoistPower
\end{tabular}

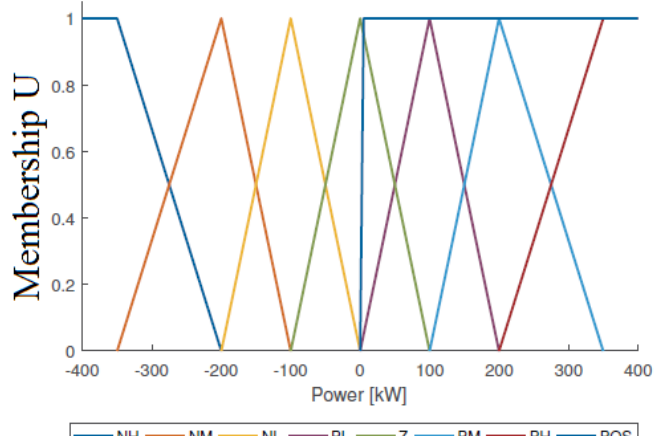

(b) input membership function 2: hoist power

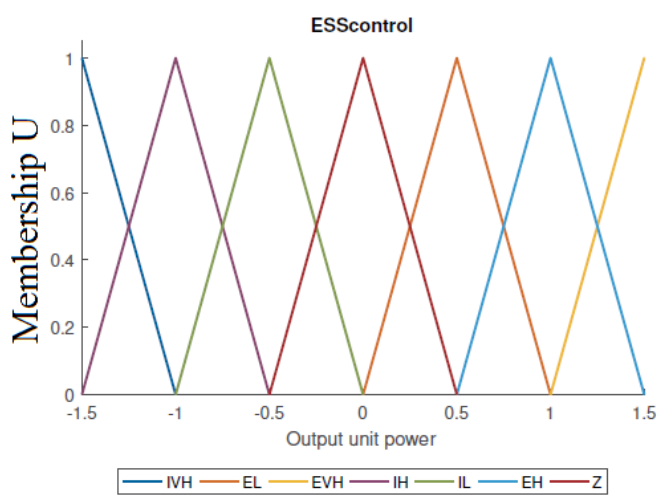

(d) output membership function: ESS unit power 
Figure 7. Membership functions of the Fuzzy Logic Controller.

\subsection{Rules.}

The Mamdami type FLC is characterised by linguistic rules that link fuzzy states to output fuzzy states using logic and if/then operators [16]. An input state, or a combination of input states, can then activate an output state with a degree that depends on the degree of membership of the input states. This process, called inference, determines the degree of firing of each rule [15].

In this paper, the rules chosen for the FLC in Table 3 are divided into four categories: import rules, export rules, idle rules and input-space filling rule. The first category relates to the import phase: the storage absorbs power that is generated by the hoist motor when lowering a container. All the 4 rules in this category begin with negating the highSpeed set for the input FESSspeed, indicating that the flywheel speed must not be too high in order to activate this rule. The first two rules link a DC voltage input state (VH or $\mathbf{H})$ into a corresponding output state (IH and IL), so the ESS will absorb power with an intensity that depends on the voltage level of the DC bus. Rules 1c and 1d are activated by the hoist motor power being negative (with varying intensity), and also by the DC bus voltage not being very low; the effect is that the control output will increase the imported power as the hoist regenerates more power.

The second category relates to the export phase: the hoist motor starts demanding power (and HoistPower is positive). All the three rules in this category include a check for FESSspeed: the rule decreases the degree of firing as the speed enters the lowSpeed fuzzy state. They also include a check on the DC bus voltage level: if it is very high, the rules are not fired, because that would indicate an excessive storage power output which causes an undesired increase in DC bus voltage. The three rules differ only by the HoistPower fuzzy set: as the hoist power decreases (from PH to PL) the control output goes from EVH to EL, thus decreasing the ESS power output; this will cause the storage to output power depending on the intensity of the demand.

The third category defines the logic that limits the control output magnitude. Rule 3 a checks that the hoist motor power is not positive (which would indicate a power demand) while also checking if the voltage level is in normal state. If that is the case, then the output state selected is zero $(\mathbf{Z})$. Similarly, the second rule of this category inhibits the storage when the voltage is low with a simultaneously negative hoist motor power. The reason behind those two rules is to limit the activity of the storage when the hoist motor has not yet increased the DC bus voltage to a level above the rectifier activation threshold. The last rule of this category is trivial: if the host motor power is zero and the DC bus voltage is normal, then do nothing. The last category has only one rule and its purpose is to fill the input space so every combination of inputs is mapped into an output, ensuring there are no ambiguous situations where no rule is firing. Note that this is the only rule that has weight different than 1: the low weight ensures minimal impact of this rule on the FLC global output. In summary, the import rules determine the storage output based on the DC bus voltage measurement, whilst the export rules are mostly based on the hoist motor power. The idle rules determine the conditions where the storage needs to stop outputting power whilst the input-space filling rule is only used to avoid ambiguous output conditions. Table 3 presents the rules in a tabular form which helps visualise the logic. 
Table 3. Rules defined for the FLC.

\begin{tabular}{|c|c|c|c|c|c|}
\hline Rule & FESSspeed & HoistPower & DCbus & ESScontrol & weight \\
\hline $1 \mathrm{a}$ & \multirow{4}{*}{ not highSpeed } & & $\mathrm{VH}$ & $\mathrm{IH}$ & 1 \\
\hline $1 b$ & & & $\mathrm{H}$ & IL & 1 \\
\hline 1c & & $\mathrm{NH}$ & $\operatorname{not} \mathrm{Z}$ & IVH & 1 \\
\hline $1 d$ & & NM & $\operatorname{not} \mathrm{Z}$ & $\mathrm{IH}$ & 1 \\
\hline $2 \mathrm{a}$ & \multirow{3}{*}{ not lowSpeed } & $\mathrm{PH}$ & not VH & $\mathrm{EVH}$ & 1 \\
\hline $2 b$ & & PM & not VH & $\mathrm{EH}$ & 1 \\
\hline $2 \mathrm{c}$ & & PL & not VH & EL & 1 \\
\hline $3 a$ & \multirow{3}{*}{ not lowSpeed } & not POS & $\mathrm{N}$ & $\mathrm{Z}$ & 1 \\
\hline $3 b$ & & not POS & $\mathrm{L}$ & $\mathrm{Z}$ & 1 \\
\hline $3 \mathrm{c}$ & & $\mathrm{Z}$ & $\mathrm{N}$ & $\mathrm{Z}$ & 1 \\
\hline $4 a$ & not normalSpeed & & & $\operatorname{not} \mathrm{Z}$ & 0.01 \\
\hline
\end{tabular}

\subsection{Defuzzification.}

The fired rules will produce a collection of recommendations, each produced by the implied fuzzy set associated with each rule. When multiple rules associated with the same output fuzzy set are fired, only the one with the highest weighted degree of firing is considered. The method chosen in this work is the centroid [15,16], which is the center of gravity of the area, and the crisp output is the output value associated with that particular point. Note that the centroid and bisection methods result in the same output if the shape of the area is vertically symmetrical. The appendix lists the membership functions linked to the FLC output.

\subsection{The output.}

The FLC controller output is truncated to the range [-1,1] which correspond to the normalised ESS power output. Figure 8 shows the FLC output when the flywheel speed is in the normalSpeed range, which is the operating state where the storage can both import and export energy. This three-dimensional figure shows what is the output of the controller (ESScontrol) with respect to two inputs: instantaneous hoist power in W (HoistPower) and instantaneous DC bus voltage in V (DCbusV). For example, at a normal flywheel speed with an hoist power of around $100 \mathrm{~kW}$ and a DC bus voltage of approximately $600 \mathrm{~V}$, the controller will output 0.4 , corresponding to a $40 \%$ positive ESS power output. The figure shows that, in general, the output of the FLC is positive when the hoist power is positive and the DC bus voltage is below $600 \mathrm{~V}$, as this corresponds to the lifting phase when the hoist motor demands power. Conversely, the output is negative when the motor power is negative and, most importantly, when the voltage approaches its higher value, thus indicating that the crane is lowering a container and the storage can be charged. 


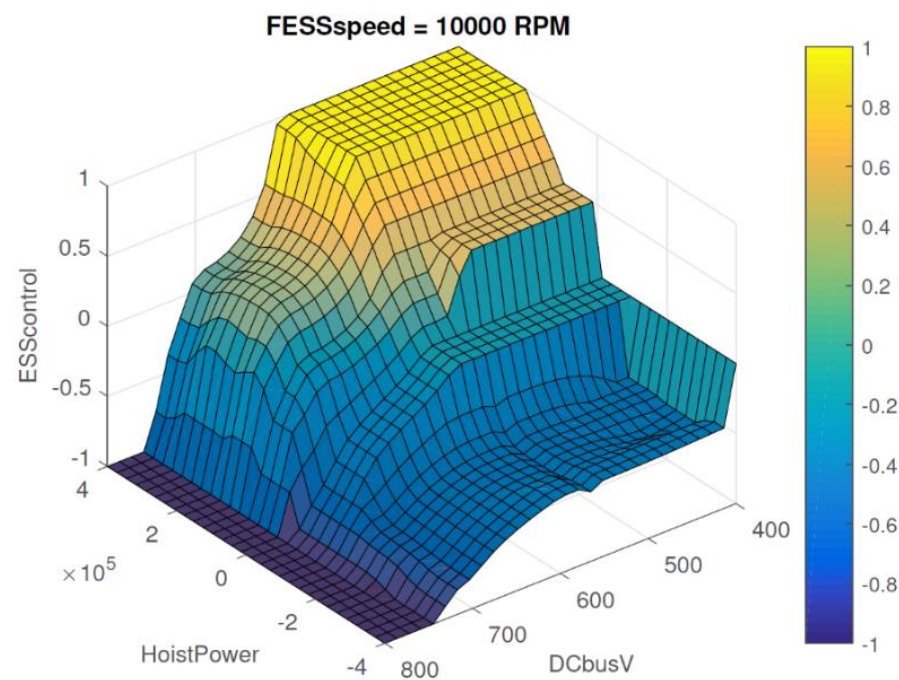

Figure 8. Output of the Fuzzy Logic Controller when the flywheel is in the normal speed range. The output value is limited to the interval $[-1,1]$.

The output of the FLC changes dramatically when the speed of the flywheel is very low $(<5000)$ or very high (>15000): positive outputs should not be allowed in the first case, whilst it is the opposite for the second case. Figure9 shows how it is the case, as ESScontrol is non-positive in Figure 11a and it is non-negative in Figure 11b. The aforementioned figures show the output for any combination of voltage and power, showing a clear trend: the output reaches its maximum when voltage is low and hoist motor power is positive. As voltage decreases and hoist power decreases, the output becomes negative.

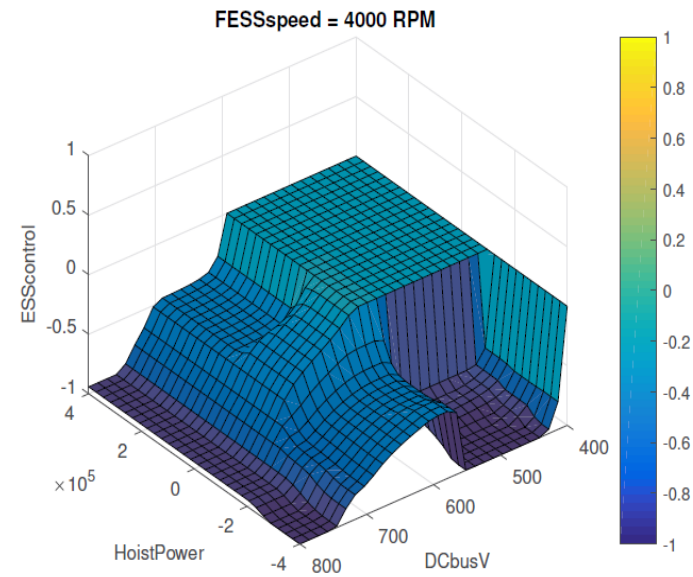

(a) low speed

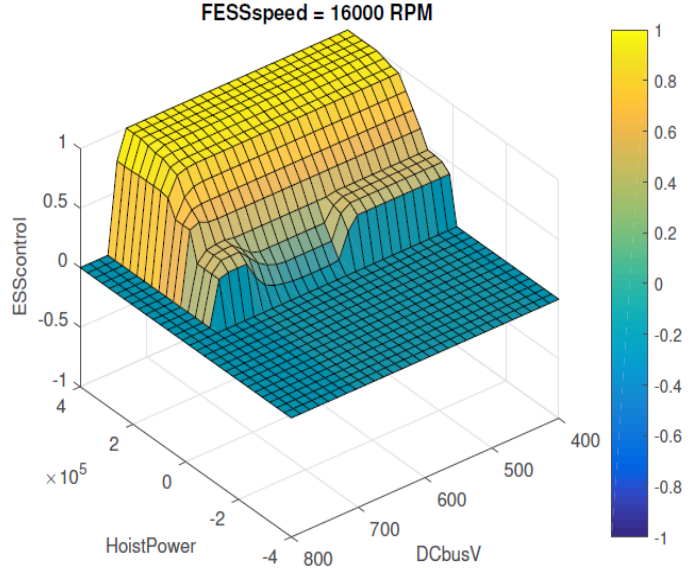

(b) high speed

Figure 9. Output of the Fuzzy Logic Controller when the flywheel speed is lower than the minimum (a) and higher than the maximum (b). The output value is limited to the interval [-1,1].

The output of the fuzzy controller in this work depends on the whole input space, but it is expected to concentrate its activity in a relatively narrow area as DC bus voltage and hoist power are not independent. During normal activity, DC bus voltage is low when hoist power is positive and vice-versa. This is more evident in Figure 10, where the voltage and power measured on a crane during typical operation have been superimposed on the output of the FLC. Not all rules will fire at the same time, and some rules will exclude others as they will be pertinent to separate fuzzy sets of the inputs. However, as mentioned above, some states of 
the system are more common due to the dynamics of the electrical components of the crane. For example, the DC bus voltage will necessarily be over a certain threshold when the hoist motor is regenerating power into it. Vice-versa, when the hoist motor is drawing power from the bus it will cause the DC bus voltage to drop below the activation threshold of the rectifier diodes. Nonetheless, the fuzzy logic strategy presented in this paper has been designed to completely fill the input space, therefore every input combination is associated with a valid output state, regardless of the probability of it happening. The surjective property of this fuzzy logic is necessary to avoid any undefined output state but also improves the transitions between more common states.

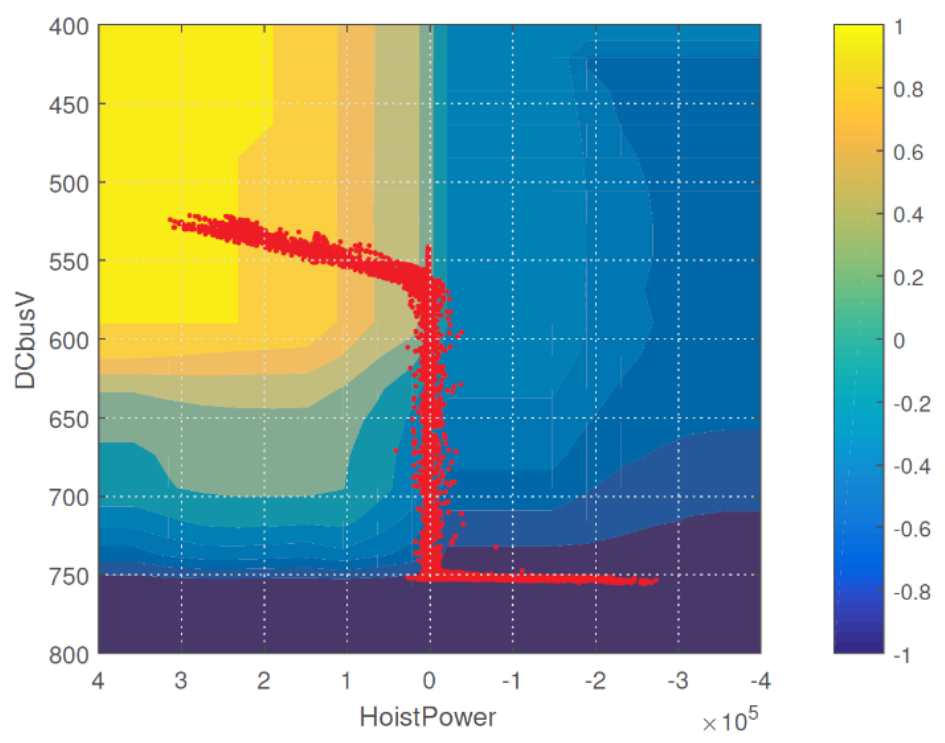

Figure 10. Hoist power vs. DC bus voltage (in red, measured during the activity of the RTG crane) superimposed on the output logic of the Fuzzy Logic Controller when the flywheel is in the normal speed range.

\section{Results and Discussions}

\subsection{The RTG crane data and test cycle.}

The FLC was implemented in Simulink and tested with the ESS model presented in Section 2. The output of the controller was multiplied by the maximum power output of the storage Ps and used as the input of the storage. An RTG crane in use at the Port of Felixstowe (described in Section 2) was recorded for 6 days during normal daily activity using bespoke measuring equipment [26]. The data obtained represents typical crane activity, including approximately 3000 container movements, real idle time and gantry movements. The data has been analysed and fed into the Simulink model for the flywheel storage system and RTG crane presented in Section 2. All the scenarios are simulated using the same data (power, energy, storage starting energy, system parameters) which lasts exactly 514950 seconds ( 5 days, 23 hours, 2 minutes, 30 seconds). Figure 11 shows the energy consumption of the RTG crane in the 6 days that compose the simulation. The simulation was repeated and tested with different ESS scenarios as follows:

- No ESS: this is the normal operation for the RTG crane system with no ESS is installed. In this scenario, the recovered energy during lowering the container is dissipated as heat through the brake resistors. 
- DC voltage PI controller: a control strategy based on the DC voltage level [11] has been developed and implemented in Simulink and it has been connected to the FESS model presented in Section 2. The controller provides a power reference to the energy storage with the objective of maintaining the DC bus voltage to a predetermined target $\mathrm{V}_{\mathrm{M}}$. This basic strategy has been demonstrated in $[8,15]$ and the parameters of the PI controller are presented in Table 4. The slow dynamics, inherent stability and simplicity of the crane electrical subsystem resulted in a fast tuning process that can be replicated with little effort on a different crane

- Fuzzy logic controller: a flywheel storage device with the FLC strategy proposed in this paper.

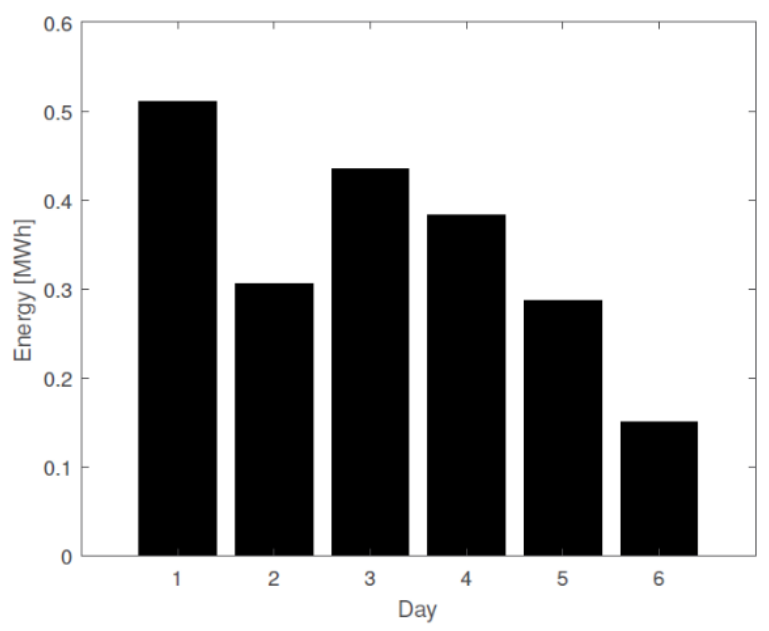

Figure 11. Energy consumption of the hybrid RTG crane in the six days recorded.

Table 4. PI controller parameters .

\begin{tabular}{rcc}
\hline Controller & Parameter & Value \\
\hline \multirow{2}{*}{ DC voltage PI } & $\boldsymbol{K}_{\boldsymbol{p}}$ & 0.01 \\
& $\boldsymbol{K}_{\boldsymbol{i}}$ & 0.1 \\
& $\boldsymbol{V}_{\boldsymbol{M}}$ & $650 \mathrm{~V}$ \\
\hline
\end{tabular}

\subsection{Energy consumption.}

The results obtained from the simulations will quantify the performance of the FLC strategy in the data set used, allowing a comparison with the common control model (PI control). The length of the simulation and the high number of lift cycles, as presented in Section 4.1, increase the chance of simulating every possible lift cycle. Furthermore, the crane was recorded during typical activity in normal operating conditions. Figure 12 presents the energy consumed by the crane under the three different scenarios. Without an ESS, the crane consumes 2.07 MWh whilst under the PI (DCV) case it would only consume 1.60 MWh. However, the fuzzy logic controller achieves the best performance, with a reduction of $31.6 \%$ compared to the $22.91 \%$ of the PI (DCV) controller. The results show a reduced energy consumption in a hybrid crane, an improvement from the baseline regardless of the control strategy implemented. However, this will not be the same with another indicator: peak power demand. The full energy results are displayed in Table 5. 


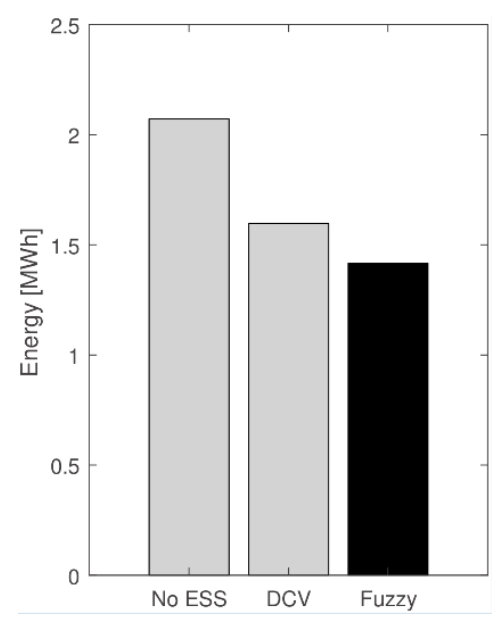

Figure 12. Energy consumption of the hybrid RTG crane in the three scenarios.

Table 5. Results of the simulation: energy consumption.

\begin{tabular}{ccc}
\hline Scenario & Energy consumed [MWh] & Reduction w.r.t no ESS \\
\hline NO ESS & 2.07 & $0 \%$ \\
PI (DCV) & 1.60 & $22.91 \%$ \\
FLC & 1.42 & $31.61 \%$ \\
\hline
\end{tabular}

\subsection{Estimated fuel consumption}

Fuel consumption was not measured directly on the RTG crane; however, it can be estimated from power consumption. Fuel is consumed both when moving container and when waiting idling for a new task. Most RTG cranes automatically shut down the diesel generator after a certain amount of time with no activity, therefore the generator will not always be consuming fuel. This issue is not present in electric-RTG cranes because they are powered by the local power network and do not need an idling diesel generator. It was not possible to meter the diesel generator; therefore, it is not known when it had been idling or shut down. For this reason, the decision was made to simulate the worst-case scenario consisting of the diesel generator always on and either idling or actively powering the crane. Whilst unrealistic, this condition is associated with the highest fuel consumption and also the least benefits of the ESS: the flywheel storage chosen for this research does not provide benefits during idling. The results, presented in Table 6, show that reach the fuzzy logic control with $8.07 \%$ fuel saving is the best performing compared to PI (DCV) controller.

Table 6. Results of the simulation: fuel consumption.

\begin{tabular}{ccc}
\hline Scenario & Fuel consumed $[\mathrm{kg}]$ & Reduction w.r.t no ESS \\
\hline NO ESS & 1306 & $0 \%$ \\
& 1232 & $5.64 \%$ \\
PI(DCV) & 1201 & $8.07 \%$ \\
FLC & & \\
\hline
\end{tabular}

\subsection{Impact on the ESS}

Shifting the focus from the crane to the energy storage device, it is useful to investigate the impact the control strategies have on the ESS. A flywheel storage device maintenance schedule and lifetime depend on the activity the controller subjects it to. One indicator of the impact on the ESS is the average power output as it correlates with reduced lifetime of the electric machine (due to wear on the mechanical components). The average power 
output was calculated as the sum of the absolute value of the output divided by the total time. The results, shown in Figure 13a, indicate that the fuzzy controller puts the ESS under the highest stress with an average power of $8.37 \mathrm{~kW}$, whilst the PI (DCV) controller have $6.89 \mathrm{~kW}$.

A second indicator of the stress applied to the ESS is the average state of charge. A flywheel storage degrades faster when the rotational speed is kept high, because of the wear on the mechanical components (bearing, motor rotor, shaft, flywheel). Figure 13b presents the average charge hold by the storage depending on the control strategy. These results are similar to the ones about average power (described above). The PI (DCV) controller provides the best results with an average stored energy of $0.46 \mathrm{MJ}$ (approximately $6100 \mathrm{RPM}$ ) compared to fuzzy logic controller with $0.76 \mathrm{MJ}$ (7650 RM). From these results it is possible to deduce that the FLC controller can help to increase the lifetime of the storage device when compared to the PI controller.

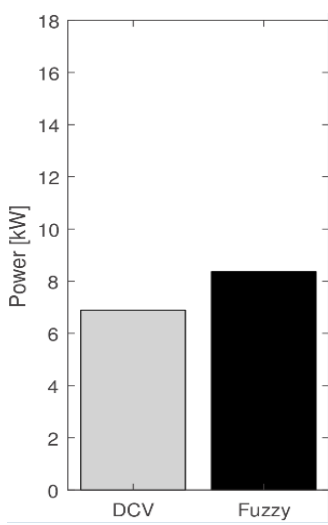

(a)

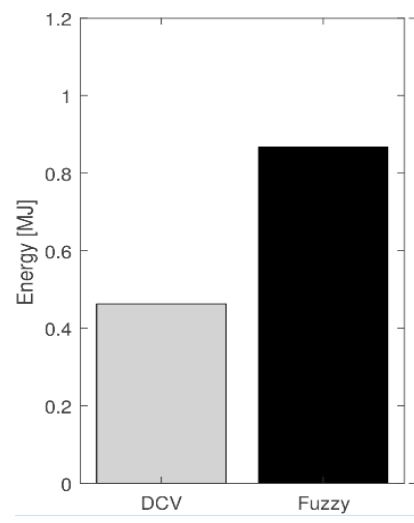

(b)

Figure 13. The control impact on the ESS (a) average absolute power output of the ESS under the PI (DCV) and Fuzzy controllers. (b) average energy stored in the ESS under the PI (DCV) and Fuzzy controllers.

\subsection{Fuzzy logic controller: further detail of the results}

The fuzzy logic control model has been successfully reduced the peak demand and energy consumption as previously discussed and shown in Figure 14. The energy consumed by the crane reached a total of $20.19 \mathrm{kWh}$, corresponding to a $32 \%$ reduction with respect to a crane not equipped with ESS.

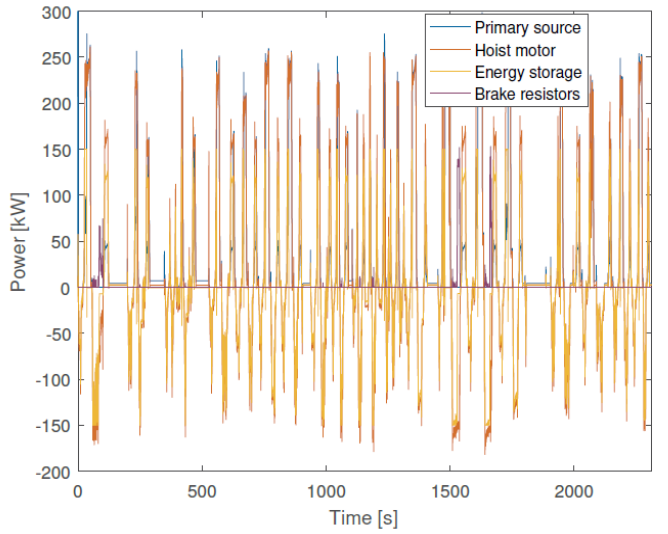

(a) power flows

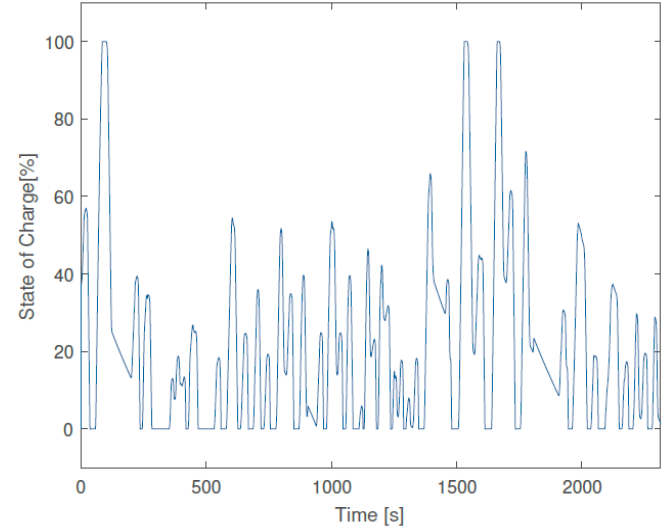

(b) energy stored

Figure 14. Results from the full simulation using the Fuzzy Logic Control. 
In the single lift cycle shown in Figure 15 the FLC shows similar behaviour to the PI and optimal controller. In the first spreader lowering, the first 20 seconds of the cycle, the ESS successfully recovers the regenerated power without causing the activation of the brake resistors. During the container lift (from second 20 to 55) the storage outputs maximum power whenever the hoist motor demands high power, until the depletion of the stored energy (Figure 15b). Although being characterised by a completely different control architecture, the FLC behaves as the PI controller during the container lowering, successfully absorbing the regenerated energy until the storage is full. The spreader lift (from 95 to 120 seconds) shows the ESS outputting power proportionally to the hoist power demand: this clearly shows the effect of the export rules, which activate a different output state (EVH, EH or EL) depending on the HoistPower input state (PH, PM or PL).

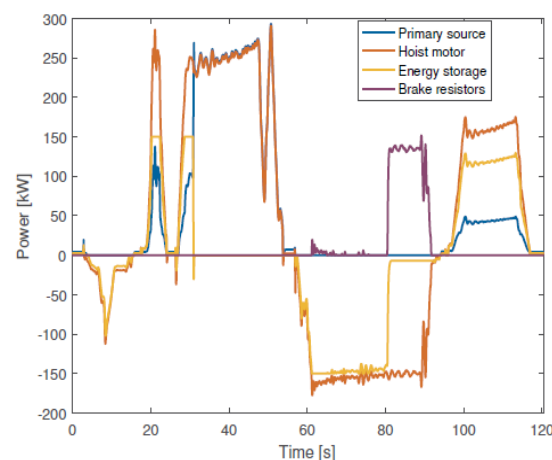

(a) power flows

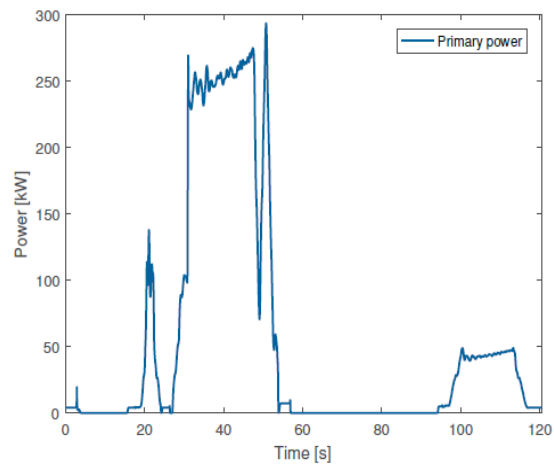

(c) primary power demand

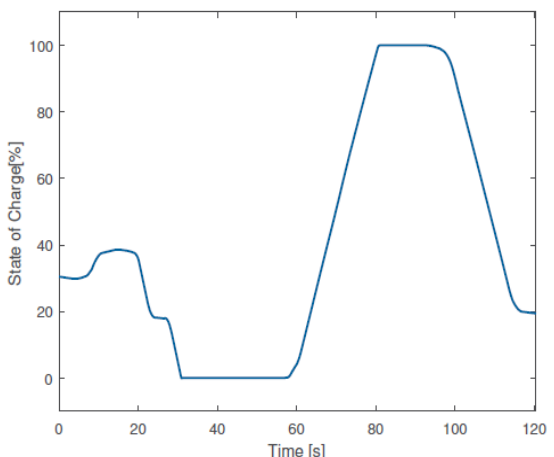

(b) energy stored

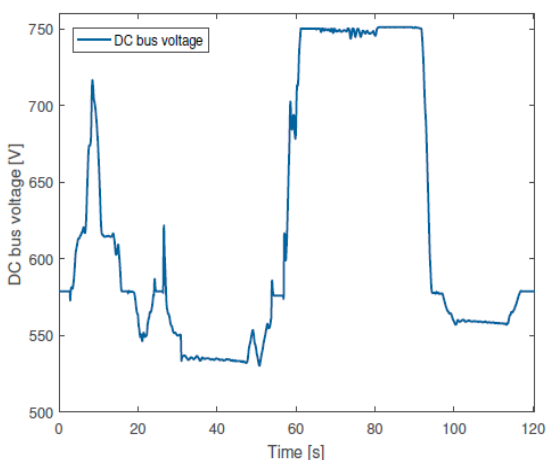

(d) DC bus voltage

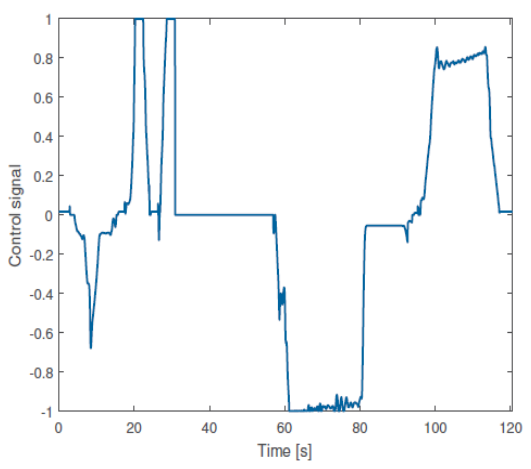

(e) control signal

Figure 15. Results from the full simulation using the Fuzzy Logic Control, single lift cycle. 
Figure 16 shows in detail the underlining process that causes this behaviour, focusing on two peculiar input states. The first input state, L1, happens at around 100 seconds in the lift cycle and is characterised by a hoist motor demand of $150 \mathrm{~kW}$; the second state, L2, is at the end of the lift at around 115 seconds, when the demand is $170 \mathrm{~kW}$. In this example, export rules $2 \mathrm{~b}$ and $2 \mathrm{c}$ are active, with the output state $\mathbf{E H}$ linked to PH and with EL linked to PM. Given the conditions of the inputs in the states L1 and L2, in this particular example the rules can be simplified as follows:

- $\quad \mathbf{R} 2 \mathbf{b}$ : if HoistPower is $\mathbf{P H}$ then ESScontrol is $\mathbf{E H}$;

- $\quad \mathbf{R} 2 \mathbf{c}$ : if HoistPower is PM then ESScontrol is EL.

Figure 16a shows the fuzzification process for both states L1 and L2. For the first state the degree of membership of $150 \mathrm{~kW}$ in PL and PM is the same: $\mu=0.5$. Rules $2 \mathrm{~b}$ and $2 \mathrm{c}$ are then both active with the same degree of firing of 0.5, and this results in the output states EH and EL being both active with maximum value $\mu=0.5$ (Figure 16b). The resulting centroid is linked to a crisp output value of $\mu=0.75$. For the second state, PM has a higher degree (0.7) than PL (0.3), therefore EH will be predominant, and this is reflected in the output being different from L1, as the crisp output has value $\mu=0.833$. The ESS output in L1 should then be 0.75 Ps which has a value of $112.5 \mathrm{~kW}$, whilst in L2 the output should be 0.833 Ps which is equivalent to $124.95 \mathrm{~kW}$. A $20 \mathrm{~kW}$ difference in the input then caused a $12.45 \mathrm{~kW}$ difference in the ESS output due to the various degree of activation of the fuzzy sets.

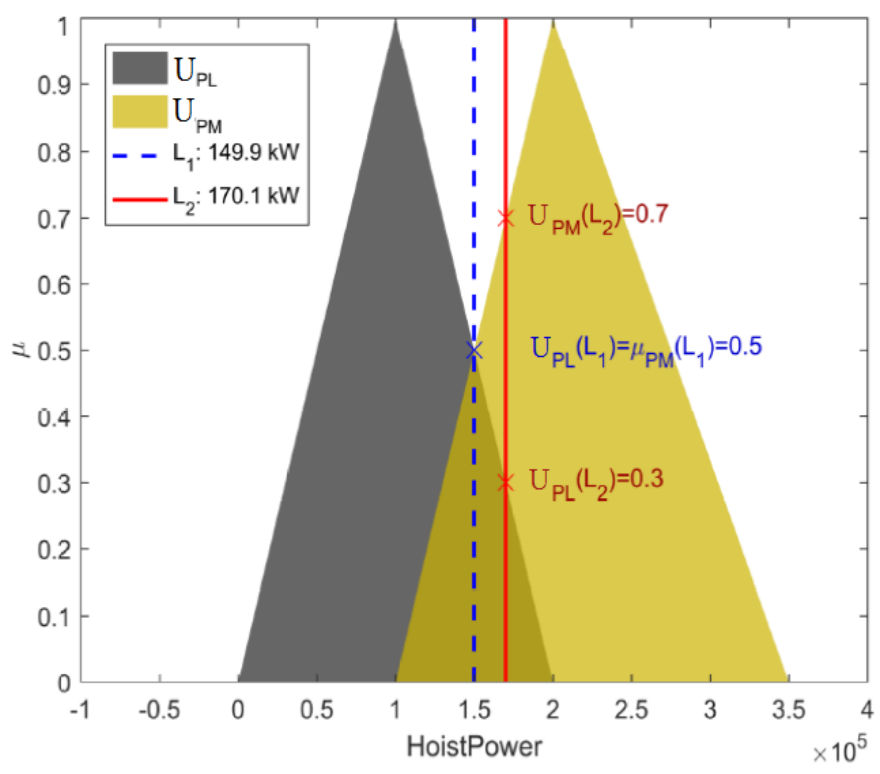

(a) fuzzification

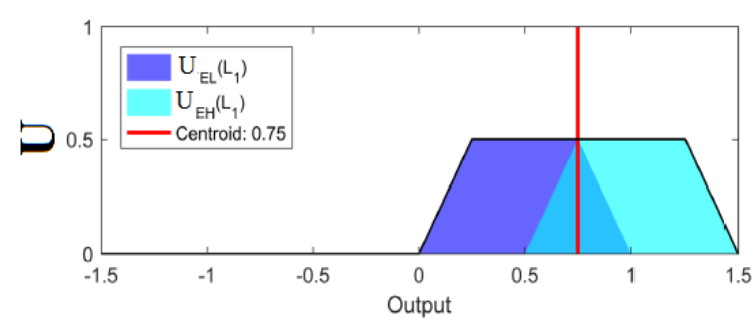

(b) defuzzification of $L_{1}$

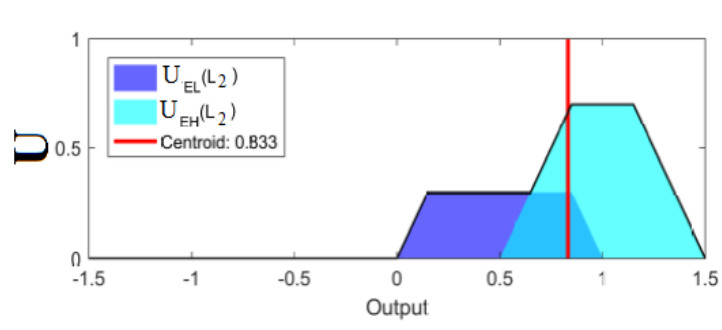

(c) defuzzification of $L_{2}$

Figure 16. Example of the fuzzy logic process for 2 peculiar states. 


\section{Conclusions}

This paper has introduced a fuzzy logic controller based on linguistic rules that describe the desired behaviour of the ESS under certain conditions, ensuring an effective operation of the storage for RTG crane application. The fuzzy logic controller has been tested, showing the desired behaviour of the storage and resulting in a reduced energy consumption. Furthermore, the fuzzy controller has been compared to common standard control system for crane and ESS applications (PI-DCV). The results showed a significant energy saving by $32 \%$ and reduced the estimated fuel consumption by $8 \%$ compared to $22 \%$ and $6 \%$ for PI (DCV) controller, respectively. The fuzzy logic controllers presented in the work have established the ability to which an energy storage device controller model can be an effective and significant solution to improve the ESS performance for RTG cranes at ports. This control approach incorporates a novel aspect to control the ESS equipped with RTG crane for reducing peak demand, energy consumptions and costs. However, the results show that the PI (DCV) controller can help to increase the lifetime of the storage device when compared to the fuzzy controller. The implementation of the fuzzy logic controllers for ESS at container port is part of future works.

\section{ACKNOWLEDGMENTS}

We would like to acknowledge the support of to the port of Felixstowe staff during collecting the data and providing all technical information. The FLC and ESS models has been developed by Stefano Pietrosanti and it was subject of his $\mathrm{PhD}$ thesis.

\section{References}

1. V. Papaioannou, S. Pietrosanti, W. Holderbaum, V. Becerra and R. Mayer. Analysis of energy usage for RTG cranes. Energy, 125, 337-344, 2017.

2. X. Liang and T. Virvalo. An energy recovery system for a hydraulic crane. Proc. Inst. Mech. Eng. Part C J. Mech. Eng. Sci., 215(6):737-744, Jan 2001.

3. H. A. Toliyat, S. Talebi, P. McMullen, Co Huynh, and A. Filatov. Advanced highspeed flywheel energy storage systems for pulsed power applications. In IEEE Electr. Sh. Technol. Symp. 2005., pages 379-386. IEEE, 2005.

4. M. M. Flynn, P. McMullen, and O. Solis. High-speed flywheel and motor drive operation for energy recovery in a mobile gantry crane. Conf. Proc. - IEEE Appl. Power Electron. Conf. Expo. - APEC, pages 1151-1157, 2007.

5. VYCON REGEN Kinetic Energy Recycling Systems. https://www.calnetix.com/regen-kinetic-energy-storage-system. Last accessed 2017-12-03.

6. Sang-Min Kim and Seung-Ki Sul. Control of Rubber Tyred Gantry Crane with Energy Storage Based on Supercapacitor Bank. In IEEE 36th Conf. Power Electron. Spec. 2005, volume 21, pages 262-268. IEEE, 2006.

7. F. Baalbergen, P. Bauer, and J. A. Ferreira. Energy Storage and Power Management for Typical 4Q-Load. IEEE Trans. Ind. Electron., 56(5):1485-1498, May 2009.

8. F. R. Salmasi. Control Strategies for Hybrid Electric Vehicles: Evolution, Classification, Comparison, and Future Trends. IEEE Trans. Veh. Technol., 56(5):2393-2404, Sep 2007.

9. D. Iannuzzi, L. Piegari, and P. Tricoli. Use of supercapacitors for energy saving in overhead travelling crane drives. In 2009 Int. Conf. Clean Electr. Power, pages 562-568. IEEE, Jun 2009.

10. W. Niu, X. Huang, F. Yuan, N. Schofield, L. Xu, J. Chu, and W. Gu. Sizing of Energy System of a Hybrid Lithium Battery RTG Crane. IEEE Trans. Power Electron., 8993(c):1-1, 2016.

11. S. Pietrosanti, W. Holderbaum, V. Becerra, Optimal Power Management Strategy for Energy Storage with Stochastic Loads. Energies $2016,9,175$.

12. H. Hellendoorn, S. Mulder, and B. D. Schutter. Hybrid Control of Container Cranes. IFAC Proc. Vol., 44(1):9697-9702, Jan 2011. 
13. M. Antonelli, M. Ceraolo, U. Desideri, G. Lutzemberger, and L. Sani. Hybridization of rubber tired gantry (RTG) cranes. J. Energy Storage, 12:186-195, 2017.

14. P. Pisu and G. Rizzoni. A comparative study of supervisory control strategies for hybrid electric vehicles. Control Syst. Technol. IEEE, 15(3):506-518, 2007.

15. J. H. Lilly. Fuzzy Control and Identification. Wiley, 2011.

16. E. H. Mamdani and S. Assilian. An experiment in linguistic synthesis with a fuzzy logic controller. Int. J. Man. Mach. Stud., 7(1):113, Jan 1975.

17. J. Lagorse, M. G. Simoes, and A. Miraoui. A Multiagent Fuzzy-Logic-Based Energy Management of Hybrid Systems. IEEE Trans. Ind. Appl., 45(6):2123-2129, 2009.

18. J. Xu, J. Yang, and J. Gao. An integrated kinetic energy recovery system for peak power transfer in 3-DOF mobile crane robot. In 2011 IEEE/SICE Int. Symp. Syst. Integr., pages 330-335. IEEE, Dec 2011.

19. N. J. Schouten, M. A. Salman, and N. A. Kheir. Fuzzy logic control for parallel hybrid vehicles. IEEE Trans. Control Syst. Technol., 10(3):460-468, May 2002.

20. A. A. Ferreira, J. A. Pomilio, G. Spiazzi, and L. de Araujo Silva. Energy Management Fuzzy Logic Supervisory for Electric Vehicle Power Supplies System. IEEE Trans. Power Electron., 23(1):107-115, Jan 2008.

21. C. Knight, V. Becerra, W. Holderbaum, and R. Mayer. Development and deployment of a control system for energy storage. pages 39, 2013.

22. C. Knight. Fuzzy logic control of a flywheel energy storage system for DRTG crane application. thesis, University of Reading, 2015.

23. Environment Report 2014-15. Technical report, Port of Felixstowe, 2014.

24. K. M. Abraham. Rechargeable lithium batteries-An overview. In Recharg. Lithium Batter., volume 1, pages 1-20, 1990.

25. I. Harrison, S. Pietrosanti, A. Luque, R. Mayer and W. Holderbaum. Recording and analysing measurements from an RTG crane. Measurement, 125, 284-293, 2018. 


\section{Appendix: Input and output membership functions}

Hoist speed in RPM (input)

$$
\begin{aligned}
& \left.\mu_{\text {lowspeed }} \text { FESSspeed }\right)=\left\{\begin{array}{cc}
1, & \text { FESSspeed }<5000 \\
-\frac{\text { FESSspeed }}{200}+\frac{5200}{200}, & 5000 \leq \text { FESSspeed }<5200 \\
0, & \text { otherwise }
\end{array}\right. \\
& \mu_{\text {normalspeed }}(\text { FESSspeed })=\left\{\begin{array}{cc}
0, & \text { FESSspeed }<5000 \\
\frac{\text { FESSspeed }}{200}-\frac{5000}{200}, & 5000 \leq \text { FESSspeed }<5200 \\
1, & 5200 \leq \text { FESSspeed }<14800 \\
-\frac{\text { FESSspeed }}{200}+\frac{15000}{200}, & 14800 \leq \text { FESSspeed }<15000 \\
0, & \text { FESSspeed } \geq 15000
\end{array}\right. \\
& \mu_{\text {highspeed }}(\text { FESSspeed })=\left\{\begin{array}{cc}
0, & \text { FESSspeed }<14800 \\
\frac{\text { FESSspeed }}{200}-\frac{14800}{200}, & 14800 \leq \text { FESSspeed }<15000 \\
1, & \text { FESSspeed } \geq 15000
\end{array}\right.
\end{aligned}
$$

\section{Hoist power in W (input)}

$$
\begin{aligned}
& \mu_{N H}(\text { HoistPower })=\left\{\begin{array}{cc}
1, & \text { HoistPower }<-350000 \\
-\frac{\text { HoistPower }}{150000}-\frac{200000}{150000}, & -350000 \leq \text { HoistPower }<-200000 \\
0, & \text { otherwise }
\end{array}\right. \\
& \mu_{N M}(\text { HoistPower })=\left\{\begin{array}{cc}
\frac{\text { HoistPower }}{150000}+\frac{350000}{150000}, & -350000 \leq \text { HoistPower }<-200000 \\
-\frac{\text { HoistPower }}{100000}-\frac{100000}{100000}, & -200000 \leq \text { HoistPower }<-100000 \\
0, & \text { otherwise }
\end{array}\right. \\
& \mu_{N L}(\text { HoistPower })=\left\{\begin{array}{cc}
\frac{\text { HoistPower }}{100000}+\frac{200000}{100000}, & -200000 \leq \text { HoistPower }<-100000 \\
\frac{\text { HoistPower }}{100000}, & -100000 \leq \text { HoistPower }<0 \\
0, & \text { otherwise }
\end{array}\right. \\
& \mu_{P L}(\text { HoistPower })=\left\{\begin{array}{cc}
\frac{\text { HoistPower }}{100000}, & 0 \leq \text { HoistPower }<100000 \\
-\frac{\text { HoistPower }}{100000}+\frac{200000}{100000}, & 100000 \leq \text { HoistPower }<200000 \\
0, & \text { otherwise }
\end{array}\right. \\
& \mu_{Z}(\text { HoistPower })=\left\{\begin{array}{cc}
\frac{\text { HoistPower }}{100000}+\frac{100000}{100000}, & -100000 \leq \text { HoistPower }<0 \\
-\frac{\text { HoistPower }}{100000}+\frac{100000}{100000}, & 0 \leq \text { HoistPower }<100000 \\
0, & \text { otherwise }
\end{array}\right. \\
& \mu_{P M}(\text { HoistPower })=\left\{\begin{array}{cc}
\frac{\text { HoistPower }}{100000}-\frac{100000}{100000}, & 100000 \leq \text { HoistPower }<200000 \\
-\frac{\text { HoistPower }}{150000}+\frac{350000}{150000}, & 200000 \leq \text { HoistPower }<350000 \\
0, & \text { otherwise }
\end{array}\right. \\
& \mu_{P H}(\text { HoistPower })=\left\{\begin{array}{cc}
0, & \text { HoistPower }<200000 \\
\frac{\text { HoistPower }}{150000}-\frac{200000}{150000}, & 200000 \leq \text { HoistPower }<350000 \\
1, & \text { HoistPower } \geq 350000
\end{array}\right.
\end{aligned}
$$




$$
\mu_{\text {POS }}(\text { HoistPower })=\left\{\begin{array}{cc}
0, & \text { HoistPower }<0 \\
\frac{\text { HoistPower }}{5000}, & 0 \leq \text { HoistPower }<5000 \\
1, & \text { HoistPower } \geq 5000
\end{array}\right.
$$

\section{DC bus voltage in $\mathrm{V}$ (input)}

$$
\begin{aligned}
& \mu_{Z}(\text { DCbusV })=\left\{\begin{array}{cc}
0, & \text { DCbusV }<0 \\
1, & 0 \leq \text { DCbusV }<400 \\
-\frac{D C b u s V}{130}+\frac{530}{130}, & 400 \leq \text { DCbusV }<530 \\
0, & \text { DCbusV } \geq 530
\end{array}\right. \\
& \mu_{N}(\text { DCbusV })=\left\{\begin{array}{cc}
0, & \text { DCbusV }<550 \\
\frac{\text { DCbusV }}{25}-\frac{550}{25}, & 550 \leq \text { DCbusV }<575 \\
1, & 575 \leq \text { DCbusV }<600 \\
-\frac{D C b u s V}{100}+\frac{700}{100}, & 600 \leq \text { DCbusV }<700 \\
0, & \text { DCbusV } \geq 700
\end{array}\right. \\
& \mu_{L}(\text { DCbusV })=\left\{\begin{array}{cc}
0, & \text { DCbusV }<400 \\
\frac{\text { DCbusV }}{130}-\frac{400}{130}, & 400 \leq \text { DCbusV }<530 \\
1, & 530 \leq \text { DCbusV }<550 \\
-\frac{\text { CCbusV }}{25}+\frac{575}{25}, & 550 \leq \text { DCbusV }<575 \\
0, & \text { DCbusV } \geq 575
\end{array}\right. \\
& \mu_{H}(\text { DCbusV })=\left\{\begin{array}{cc}
\frac{D C b u s V}{100}-\frac{600}{100}, & 600 \leq D \text { CbusV }<700 \\
-\frac{D C b u s V}{50}+\frac{750}{50}, & 700 \leq D \text { CbusV }<750 \\
0, & \text { otherwise }
\end{array}\right. \\
& \mu_{\text {VH }}(\text { DCbusV })=\left\{\begin{array}{cc}
0, & \text { DCbusV }<700 \\
\frac{\text { DCbusV }}{50}-\frac{700}{50}, & 700 \leq \text { DCbusV }<750 \\
1, & \text { DCbusV } \geq 750
\end{array}\right.
\end{aligned}
$$

\section{FLC output}

$$
\begin{gathered}
\mu_{I V H}(i)=\left\{\begin{array}{cc}
0, & i<-2 \\
1, & -2 \leq i<-1.5 \\
-\frac{i}{0.5}-\frac{1}{0.5}, & -1.5 \leq i<-1 \\
0, & i \geq-1
\end{array}\right. \\
\mu_{E L}(i)=\left\{\begin{array}{cc}
\frac{i}{0.5}, & 0 \leq i<0.5 \\
-\frac{i}{0.5}+\frac{1}{0.5}, & 0.5 \leq i<1 \\
0, & \text { otherwise }
\end{array}\right. \\
\mu_{E V H}(i)=\left\{\begin{array}{cc}
0, & i<1 \\
\frac{i}{0.5}-\frac{1}{0.5}, & 1 \leq i<1.5 \\
1, & 1.5 \leq i<2 \\
0, & i \geq 2
\end{array}\right.
\end{gathered}
$$




$$
\begin{gathered}
\mu_{H H}(i)=\left\{\begin{array}{cc}
\frac{i}{0.5}+\frac{1.5}{0.5}, & -1.5 \leq i<-1 \\
-\frac{i}{0.5}-\frac{0.5}{0.5}, & -1 \leq i<-0.5 \\
0, & \text { otherwise }
\end{array}\right. \\
\mu_{L L}(i)=\left\{\begin{array}{cc}
\frac{i}{0.5}+\frac{1}{0.5}, & -1 \leq i<-0.5 \\
\frac{i}{0.5}, & -0.5 \leq i<0 \\
0, & \text { otherwise }
\end{array}\right. \\
\mu_{E H}(i)=\left\{\begin{array}{cc}
\frac{i}{0.5}-\frac{0.5}{0.5}, & 0.5 \leq i<1 \\
-\frac{i}{0.5}+\frac{1.5}{0.5}, & 1 \leq i<1.5 \\
0, & \text { otherwise }
\end{array}\right. \\
\mu_{Z}(i)=\left\{\begin{array}{cc}
\frac{i}{0.5}+\frac{0.5}{0.5}, & -0.5 \leq i<0 \\
-\frac{i}{0.5}+\frac{0.5}{0.5}, & 0 \leq i<0.5 \\
0, & \text { otherwise }
\end{array}\right.
\end{gathered}
$$

